\title{
Territorio liberado: la producción artística femenina en el Montevideo del Novecientos
}

\author{
Montevideo del 900: liberated territory \\ for women's artistic production
}

\section{Daniela Tomeo*}

\footnotetext{
* Profesora de Historia (IPA). Licenciada en Historia (UDELAR). Maestranda en Didáctica de la Historia (UCLAEH). Profesora de Historia del Arte en Bachillerato y en Consejo de Formación en educación (IPA). Corresponsable del Programa Historia del Arte y $\mathrm{Pa}$ trimonio de la Facultad de la Cultura (CLAEH).

凹. danielatomeo2015@gmail.com https://orcid.org/0000-00026239-8398
}

RECIBIDO: 15.4 .2020

ACEPTADO: 28.5 .2020

\section{Resumen}

El artículo propone pensar en la presencia femenina en las artes plásticas del Uruguay entre la segunda mitad del siglo XIX y la primera década del XX, y evidenciar las lógicas y los lugares desde los que la sociedad habilitaba la participación de las mujeres en el mundo del arte.

Palabras clave: artes plásticas, Uruguay, mujer artista.

\begin{abstract}
This article reflects on the presence of female plastic artists in Uruguay between the second half of the 19th century and the first decade of the $20^{\text {th }}$ century, revealing the logics as well as the places from which the society of the time enabled the participation of women in the field of arts.
\end{abstract}

Keywords: plastics arts, Uruguay, female artists. 


\section{Los territorios del quehacer artístico}

En 1981, las historiadoras Griselda Pollock y Rozsika Parker (2013) escribieron un libro con un título provocador: Old Mistresses. Women, Art and Ideology. ${ }^{1}$ El título refiere a los llamados por la historia del arte old masters o viejos maestros, término que no tiene una traducción exacta en español; old mistresses significaría 'viejas amantes' o 'mujeres viejas', y las historiadoras mencionadas no encontraban viejas maestras o antiguas maestras en el campo de las artes visuales. Lo que Parker y Pollock discuten no es solamente si hubo o no mujeres pintoras - sabemos que las hubo-, sino el lugar que tuvieron en un medio cultural e ideológico que no esperaba de ellas que fueran grandes maestros y que, por tanto, no las formaba para tal fin.

El período al que me voy a referir, segunda mitad del siglo XIX y primera década del XX, fue un tiempo en el que el sistema de enseñanza académico incluía, entre otros entrenamientos, el estudio del desnudo, lecciones a las que las mujeres no podían acceder. El sistema académico se apoyaba en un ordenamiento jerárquico de las artes liderado por las llamadas artes mayores (escultura, pintura y arquitectura), seguidas por las artes menores o decorativas, algunas de las cuales eran de dominio femenino. La historiadora Estrella de Diego (2009) se pregunta si por ser artes menores eran cultivadas por las mujeres o si eran artes menores por ser las mujeres sus productoras. Lo cierto es que sin duda las artes de la aguja — tejido, bordado y costura, en sus distintas variedades - fueron siempre un territorio liberado a las damas, y el siglo XIX no fue la excepción.

La literatura destinada a las mujeres, contenida tanto en libros escolares como en manuales dirigidos a formar buenas amas de casa, indicaba que las artes de la aguja eran no solo recomendables, sino beneficiosas para las mujeres de todas las clases sociales. A aquellas que no estaban destinadas al mundo del trabajo y que tampoco debían hacer las tareas domésticas, la aguja les daba un pasatiempo que podía articularse con las frecuentes obras de caridad en las que se involucraban. La Sociedad de Señoritas Entre Nous (1907-1919), una de las tantas agrupaciones que reunían a las mujeres de las clases altas, tenía entre sus actividades semanales un día dedicado a coser para los pobres. La historia familiar también se construía a través de imágenes producidas por mujeres, desde el lento y amoroso bordado del ajuar de boda, que enorgullecía a la novia y a su 
familia, hasta los álbumes familiares. En estos últimos se descubre una variedad de producciones visuales en las que las flores son el motivo dominante, ${ }^{2}$ flores desplegadas en papeles y telas recortadas, pequeñas litografías, marcos fotográficos. Como señala Peluffo Linari (1997): "Sus posibles significados, o el mero sentido testimonial del conjunto, solo puede apreciarse en la serie, en la secuencia iconográfica que ofrece el libro en su totalidad, como representación "condensada" del universo familiar» (p. 208).

Las mujeres de los sectores medios o populares cuyo destino era ser madres y esposas podían ayudar a la economía del hogar si dominaban la aguja, o encontrar un medio de subsistencia si no tenía la fortuna de alcanzar el matrimonio (Peruchena, 2010). La imagen de la mujer con aguja representaba a la madre laboriosa y ahorrativa, dos valores en los que se insistía una y otra vez en los libros escolares, medios de prensa o la extensa literatura destinada a la mujer publicada en el período (Barrán, 2015).

En la formación que Figari propuso para la Escuela de Artes y Oficios, lo utilitario no estaba reñido con la creatividad y la búsqueda de un diseño bello. En 1916, a raíz de la reforma figariana, se incorporó el taller denominado Labores Femeninas, que incluía la confección de alfombras, almohadones, carpetas, cortinas, guardaobjetos y panneaux, entre otros (Peluffo Linari, 2006). Las pequeñas industrias familiares que proponía Figari podrían dar a la mujer «cuyas- dificultades para vivir son notorias, elementos para luchar decorosamente» (Figari, 1965, p. 43). Los cursos nocturnos del Círculo de Bellas Artes, creado en 1905, tenían también estudiantes mujeres cuya meta no necesariamente era ser pintoras o escultoras, sino empleadas de la naciente industria.

Si ampliamos el campo del arte y legitimamos las artes industriales, decorativas o menores como prácticas artísticas válidas, sin duda las mujeres tuvieron un rol y una participación singular en la cultura visual de la época, entendida, como dice Mitchell (2017), como «la construcción social de la visión» (p. 426).

\section{Pintura histórica y retratos de hombres ilustres: fuera de la Academia}

En el sistema académico imperante en el siglo XIX, la pintura histórica fue el género más valorado. Tenía una fuerte función pedagógica, desarrollaba grandes ideas vinculadas a la historia y a la nación, y funcionaba como formadora de ciudadanía. Eran complejas composiciones en las que había que ser diestro en la pintura de paisajes y

Desde el siglo XVII, especialmente en Holanda, hubo pintoras que se especializaron en la representación naturalista de flores, plantas e insectos. El siglo XIX continuó alentando a las mujeres a incursionar en este género y a explorar dichos motivos (Parker y Pollock, 2013). 
naturaleza, animales, figuras humanas en movimiento, para cuya resolución se necesitaba, por ejemplo, tener estudios del desnudo. Las enormes dimensiones de las pinturas históricas requerían grandes estudios y generalmente asistentes o aprendices que trabajaban bajo la dirección de un maestro. La pintura histórica era, por tanto, el género consagratorio para quien aspirara a ser pintor profesional.

En el Uruguay y en América en general, fue un género que tuvo especial importancia en el período que estudiamos: grandes obras que relataban un pasado heroico y consagraban algunos hitos en la construcción de la historia nacional. El Estado aplaudió este tipo de pintura, a la vez que requirió, en el correr del siglo XIX y principios del XX, una galería de hombres ilustres que dieran rostro a los fundadores de la nación: constituyentes, criollos que abrazaron la causa revolucionaria, figuras vinculadas a la formación del nuevo Estado. El Uruguay no tenía academias de pintura, por lo que el viaje de formación europeo trató de compensar las dificultades que encontraban los artistas del medio para formarse. En ese escenario nacional, la producción iconográfica de Juan Manuel Blanes - quien estudió en la Academia florentina- fue determinante. Pintores europeos llegados al Río de la Plata también realizaron retratos de caudillos o representantes de nuestra clase política.

Era un territorio destinado a profesionales, de formación académica y, por supuesto, hombres. Sin embargo, en nuestro país, en el que hubo pocas mujeres dedicadas a la pintura, las dos primeras pintoras de las que tenemos noticia dieron rostro a figuras públicas, y una de ellas incluso fue pionera en la pintura histórica. Una de ellas es Josefa Palacios, de quien hay muy poca información. Sabemos que nació en Colonia del Sacramento, aunque no conocemos la fecha, y que murió en 1881; que su esposo era el español Manuel Gómez de la Gándara y que pintó algunos retratos, en su mayoría de paradero desconocido. Barrios Pintos (2011) identifica los de Florencio Varela, Francisco Acuña de Figueroa, María Ortiz Laguna de Argentó, su hija Argentó de Mula y el esposo de la artista, Manuel Gómez.

La obra más interesante de Palacios es una pintura histórica, El juramento de los treinta y tres patriotas orientales en el Arenal Grande el 19 de abril de 1825, ${ }^{3}$ realizada antes de 1849, ya que ese año fue comentada por El Comercio del Plata. La nota elogia la precocidad de la artista para el dibujo y la pintura, elogio que es reiterado pocos años después en Eco de la Juventud. En ambos casos se valora el esfuerzo de realizar una obra en un medio en el que el arte, la producción artística y la enseñanza de la pintura eran sumamente escasos. El Eco lo señalaba con estas palabras: «Librada a sus propios esfuerzos, careciendo de grandes maestros y de buenos modelos, y venciendo a fuerza de una constancia sorprendente, los escollos casi insuperables de un arte tan difícil» (Ferreira, 1854). 
En 1893 el cuadro ya estaba en el Museo Nacional, año en que el director de la institución decía desconocer la fecha del ingreso (Carpeta 822. Libro I. Antecedentes. MHN). En 1911, cuando el Museo Nacional se dividió en tres instituciones (Museo de Bellas Artes, Histórico y de Historia Natural), el cuadro ingresó al Museo Histórico y fue restaurado dos años después por Ernesto Laroche (Carpeta 822 Tomo I. Antecedentes MHN). La pintura fue escasamente valorada desde el punto de vista plástico, como muestra el hecho de que su destino fuera el Museo Histórico y no el de Bellas Artes. En el mismo momento, El juramento de los Treinta y Tres, de Juan Manuel Blanes, tenía como destino el Museo de Bellas Artes. Las obras se valoraron siguiendo los estándares de la producción académica, y era evidente que la pintura de Palacios no se manejaba dentro de esa tradición. En 1958 el historiador Laroche solicitó el cuadro a Juan Pivel Devoto, por entonces director del Museo Histórico, a fin de sacarle una foto que acompañaría una nota escrita para el diario El Plata (Laroche, 1958). La crónica se publicó el 18 de abril de ese año y fue posteriormente reproducida en el libro del propio Laroche Derrotero para una historia del arte en el Uruguay (1961). El análisis no era elogioso:

Los personajes, faltos de volumen, no tienen por cierto los verdaderos rasgos fisonómicos, estando muy lejos de ser individualizados como permiten serlo en el cuadro del mismo tema que realizó Juan Manuel Blanes en 1876/78, cincuenta años después del acontecimiento, documentándose en fuentes insospechables y en el mismo histórico escenario.

Corresponde señalar que la cita, no significa hacer comparaciones. El cuadro de Josefa Palacios compone una escena con paisaje imaginado, con errores de perspectiva, carente de dibujo y no resiste análisis técnicos. Pero tiene en su favor que, realizado antes de los treinta años después del hecho, reúne el sentido emocional suscitado por un acontecimiento que había tenido repercusión americana (p. 5).

La «veracidad» en el registro de los hechos y la fidelidad en la fisonomía de los personajes eran valores que, entendía Laroche, estaban ausentes en un cuadro demasiado imaginativo. Lo único rescatable de la obra, era según su entender, el «sentido emocional» que reflejaba. Pivel Devoto, por su parte, hacía comentarios similares señalando que era «ingenua», pero «no desprovista de encanto» (Pivel Devoto, 1952).

Como señala Chadwick (2007), las adjetivaciones que usan los historiadores proyectan en la pintura los valores que se atribuía a las mujeres: encanto, ingenuidad y el predominio de lo emocional sobre lo racional —este era sin duda un atributo masculino-. Dice Pollock (2015) sobre la forma en que la historiografía ha trabajado la pintura femenina: «Todo lo que esas mujeres produjeron es visto como testimonio de una única cualidad derivada de su sexo: la feminidad, y por lo tanto, como prueba de que las mujeres tienen un estado menor como artistas» (p. 63). 
La segunda pintora a la que me refería es Carmen Árraga de Sardeson (18401919), quien retrató a figuras públicas y a sus jóvenes 23 años pintó uno de los primeros retratos de José Artigas. ${ }^{4}$ Árraga fue alumna de Juan Manuel Blanes ${ }^{5}$ y conoció al pintor peruano Luis Montero, quien estuvo de paso por Montevideo en 1866, al regresar de su tercera estadía en la Academia florentina. Montero llegó al Uruguay con la obra que sería la más importante de su carrera, Los funerales de Atahualpa, que se expuso en el foyer del Teatro Solís, y pintó un retrato de Carmen, ${ }^{6}$ experiencia que habrá resultado enriquecedora para una joven pintora en formación. En 1870, la artista pintó un retrato de Joaquín Suárez que regaló a la Asamblea General, y esta le ofreció una beca para ir a estudiar en Europa durante cuatro años. Árraga no hizo uso de la beca y, cuando años después contrajo matrimonio con el inglés John Sardeson, contador del Banco de Londres, solicitó una compensación económica a cambio. Antes del matrimonio, la pintora realizó retratos de otras figuras públicas uruguayas: Tomás Gomensoro, Juan Francisco Giró, Alejandro Chucarro, así como de Venancio Flores, Juan Méndez Calderio ${ }^{7}$ y Francisco Acuña de Figueroa. Luego del matrimonio, Árraga no abandonó nunca la pintura, y en el legado familiar se conservan cuadros con retratos familiares y naturalezas muertas. $^{8}$

La obra de Elvira Reyes (1848-1930) que conserva el Museo Histórico es bien interesante en cuanto a la frontera entre lo público y lo privado por la que transitaban nuestras pintoras. ${ }^{9}$ Elvira Reyes fue una joven perteneciente al patriciado uruguayo, hija de José María Reyes y eterna novia de Julio Herrera y Obes. En 1915 recibió una carta del director del Museo Histórico Nacional, Luis Carve, quien le explicaba que en el Museo se estaba realizando una galería de retratos de personajes históricos y le solicitaba un retrato del padre de la joven, que sabía que estaba en su poder. Elvira respondió que efectivamente había un retrato pintado por Juan Manuel Blanes, en poder de su hermano, pero que ella solo tenía una copia de la obra de Blanes realizada por ella misma. Las jóvenes de los sectores acomodados acostumbraban tener un profesor de pintura, y

José Artigas (hacia 1863), óleo sobre tela, 56×40,5cm, Museo Histórico Nacional, Casa de Rivera.

En 1861 Juan Manuel Blanes escribió una carta a su hermano Mauricio desde Florencia. Allí le solicitaba que recuperara un maniquí que estaba en lo de Árraga y se lo enviara, dado que en Italia eran muy costosos (Blanes, 1861). El comentario sugiere que Blanes frecuentaba la casa de Árraga como profesor de Carmen, hasta el punto de prestarle elementos importantes para la práctica de la pintura.

8 En comunicación telefónica, la señora María del Carmen Sardeson, nieta de Carmen Árraga, afirma tener cuatro naturalezas muertas pintadas por su abuela y recordar otras obras, retratos de integrantes de la familia e incluso de una mascota (comunicación personal, 10 de abril de 2020). 
la copia de obras de pintores consagrados era uno de los ejercicios frecuentes. Seguramente fue el caso de Elvira, quien copió el retrato de su padre,$^{10}$ fallecido cuando ella tenía 16 años. Así, terminó pintando un singular retrato familiar, mediado por la obra del gran pintor uruguayo. El retrato - contestaba Elvira a Carve- es muy inferior al de Blanes en cuanto al arte, pero superior en cuanto al parecido con el modelo, valor no menor a la hora de evaluar una obra de ese género (Reyes, 1915).

\section{Las aficionadas}

Pedro Figari, un pensador atento a lo que sucedía en materia de artes en el mundo occidental, tenía clara la diferencia que había entre artes mayores y artes menores o, como él prefería llamarlas, artes industriales. Eran actividades con distintos fines, más elevados unas, más prácticos otras, que estaban destinadas a ser ejecutadas por distintos sectores sociales.

Además de las diversas Facultades superiores que tanto bien han producido en la intelectualidad nacional, habría una institución complementaria, más accesible a las clases menesterosas, en la que podría obtenerse instrucción fácil y práctica, aumentándose considerablemente la variedad de ocupaciones, y, fuera de la arquitectura, la escultura y la pintura, que en su faz superior serían acometidas por los elegidos, por los talentos excepcionales, surgirían vigorosamente las artes aplicadas, las artes decorativas que comprenden, puede decirse, la mayor parte de las manifestaciones estéticas, puesto que intervienen íntimamente en la edificación, en parques, jardines, en cerámica, tejidos, papeles, cristalería, en muebles, joyería, ebanistería, grabados, tallados, herrería, carpintería, albañilería, encuadernación, escenografía, ilustraciones, fototipia, zincografía, litografía, etc., etc. (Figari, 1965, p. 13)

Los profesionales que se dedicaran a las artes mayores, afirmaba Figari, serían aquellos elegidos y talentosos varones formados en las facultades superiores. En realidad, en nuestro país solo existía la Facultad de Arquitectura; ${ }^{11}$ no había academias de bellas artes ni para varones ni para mujeres. El recorrido que hicieron nuestros pintores tuvo básicamente dos estaciones: la primera, asistir al taller de algún pintor que se

Retrato de J. M. Reyes realizado por Elvira Reyes, 1890. Pastel. Óvalo, 53,5×43,5 cm. Donado al Museo Histórico Nacional en 1915.

11 No voy a referirme a la formación de los arquitectos. En 1886 se creó la Facultad de Matemática y Ramas Anexas, que incluía estudios de Arquitectura e Ingeniería. En 1915 ambas carreras se separaron y se creó la Facultad de Arquitectura. 
desempeñara en el medio, generalmente un europeo llegado a estas tierras; la segunda, viajar a Europa, donde sí podrían ingresar a una academia. El viaje a Europa fue en algunos casos financiado por la propia familia del pintor y en otros fue una beca otorgada por el gobierno uruguayo. En 1905 se creó el Círculo de Bellas Artes, institución privada por la que pasaron como estudiantes o como docentes casi todos los artistas nacionales que trabajaron o se formaron en la primera mitad del siglo XX, formación que no eliminó el viaje a Europa.

Para las mujeres, la primera etapa de la formación era accesible, siempre que integraran los sectores sociales privilegiados. En tal caso, era altamente probable que las jóvenes tuvieran una temprana formación artística. De hecho, señala Peluffo Linari (2015), ser alumna de un artista de prestigio era un rasgo de distinción.

Los maestros asistían a las casas de las alumnas o tenían sus propios talleres, en los que había horarios y días destinados al público femenino. Laroche (1961) identifica al menos tres pintoras que además fueron docentes: la italiana Lavinia Bolla de Cereda, quien había estudiado en la Academia de Milán y llegó a Montevideo en 1869; la francesa Mme. Bocha, quien en 1876 ya dirigía una academia de pintura por la que «desfilaron jovencitas de la sociedad montevideana que estudiaron dibujo y pintura para adorno personal muchas de ellas, sin que sus nombres tuvieran mayor trascendencia, quedando su labor reducida a aquella plausible finalidad» (p. 158), y la pintora Ángela Lebrun (1870-1916), profesora de dibujo en el Instituto Normal de Señoritas en 1893.

Lebrun participó en la Exposición de Arte Nacional de 1908 - a la que nos referiremos más adelante-, en el sector de pintores contemporáneos, con retratos de figuras públicas que le valieron una medalla de oro: Retrato de Artigas al final de su vida y Retrato de Claudio Williman. También estuvo presente y fue premiada en la Exposición de Chicago de 1893 (Laroche, 1975). Fue docente, ganó premios en eventos nacionales e internacionales, expuso junto con sus colegas varones y no en una sección especial dedicada exclusivamente a mujeres, lo que la ubica entre las pintoras profesionales. Evidentemente, las pintoras profesionales eran pocas y las aficionadas eran muchas. Juan Manuel Blanes lo definía de esta manera: «Entendemos por aficionado a pintar, al que pintando, busca solo solazarse recreativa, caprichosa, varia y agradablemente» (Peluffo Linari, 2015).

La mayoría de las pintoras aficionadas eran mujeres. El historiador Laroche (1961) se refiere a ellas utilizando términos que denotan los esencialismos con los que la historiografía ha tratado la producción femenina, aun la de las profesionales. Dice Laroche: 
[...] jóvenes de nuestra sociedad que a fines del siglo XIX agregaron a sus estudios de la música, el dibujo y de la pintura como adorno personal; generación de jovencitas que escribieron una memorable página en la cultura de aquel tiempo y que la tradición familiar ha prolongado hasta nuestros días (1961, p. 242).

La idea de la mujer como adorno se proyecta claramente en las palabras del historiador; la práctica de las bellas artes embellece a la mujer, pero su producción se guarda en el seno de la familia. Hubo algunas oportunidades en que estas mujeres lograron exponer sus obras e incluso las vieron reproducidas en semanarios o revistas ilustradas. En 1886 La Ilustración del Plata reprodujo en su primera página un grabado realizado a partir de una pintura de Josefina Cibils acompañado del siguiente comentario:

Hoy publicamos en primera página un estudio de Josefina Cibils que representó uno de nuestros antiguos paisanos, aquellos héroes de los tiempos viejos teñidos en las luchas de la patria y muertos en las guerras fratricidas. La señorita de Cibils es una de nuestras mejores aficionadas y no tememos equivocarnos llamándola artista. La reproducción artística hecha sobre piedra por el profesor Sommavilla ${ }^{12}$ puede dar una idea de lo acertado de nuestra aserción («María Luisa Velazco», 1887).

El cronista sabía que estaba ante una pintora que no era profesional ni aspiraba a serlo, pero por su talento se podía considerar una verdadera artista, lo que debe ser visto como un elogio, si bien el saldo final es que es una de las mejores aficionadas. Unos años después, otro medio de prensa reprodujo otra obra de Josefina Cibils y nuevamente el cronista quiso destacar su talento llamándola artista, un término que incomodaba a algunos por tratarse de una mujer. La justificación del periodista es elocuente: «Artista he dicho y no retiro la palabra, por más que suene mal á muchos oídos que pertenecen á la aristocracia del tiempo de los tres botones de rosa». El artista no es solo el que vende obra - fundamentaba a continuación-, sino también el que la siente. Sin embargo, una vez más, la nota terminaba reconociendo que Cibils era una de las más destacadas aficionadas a la pintura que había en nuestro país («Nuestra galería artística», 1894. deo, donde también se desempeñó como profesor de dibujo y pintura en instituciones como la Scuola Italiana, el Liceo Franco-Uruguayo y la Escuela Nacional de Artes y Oficios. Pedro Figari fue alumno de Sommavilla (Laroche, 1961). 
p. 51). ${ }^{13}$ Con talento o sin él, el campo de trabajo es claramente delimitado y definido por los contemporáneos.

En 1908 se realizó en el Club Católico de Montevideo una muestra importante, llamada Exposición de Pintores Nacionales, que tuvo como responsable artístico a Raúl Montero Bustamante. El catálogo ordena a los pintores como estaban presentados en la muestra, en cuatro secciones: Primitivos, Autores fallecidos, Contemporáneos ${ }^{14}$ y Sección Especial. ${ }^{15}$ En esta última sección se podían ver las obras de una veintena de señoras y señoritas, cuyos temas principales eran flores, paisajes, pinturas religiosas, marinas o naturalezas muertas, $\mathrm{y}$, a juzgar por los nombres de las obras, muchas eran copias de obras de grandes maestros («Catálogo de la primera», s/f).

Los apellidos de las pintoras expuestas las identifican como integrantes de los sectores altos de la sociedad; muchas de ellas integraban grupos de beneficencia o sociedades católicas. Como señala Inés Cuadro (2018), fue frecuente que las mujeres de las familias acomodadas integraran sociedades de caridad o de defensa de la religión en tiempos en que el laicismo era visto como una amenaza a la familia. La Liga de Damas Católicas tuvo principalmente este último cometido, que justificaba su acción en el ámbito público. Una de las expositoras era María García Lagos de Hughes (1874-1951), presidenta de la Liga de Damas Católicas desde su creación, en 1906, hasta 1919.16

En este escenario es razonable que las señoras que exponían sus obras lo hicieran en una sección especial, lo que les aseguraba un ambiente que no las dejaba totalmente expuestas y las separaba de los pintores profesionales. Por otra parte, el ingreso a la exposición parece haber tenido algún tipo de restricción, ya que el cronista del periódico Bohemia comentaba sobre la muestra: «[...] á la del Club Católico, á la que no he podido asistir porque es á puerta cerrada, y para mí, bohemio al fin, no existe ningún Sésamo» (Juan de los Palotes, 1908). La sección especial marca una frontera entre los pintores profesionales vivos o fallecidos y las aficionadas, quienes, aun siendo talentosas, no podían ni por género ni por clase integrar otros espacios. Carlos Reyles, en Beba (1894),

13 La pintura que se reproduce muestra a una mujer anciana junto a un muro, en una típica escena naturalista de tipos humanos. En el número siguiente se publica una obra de la señorita Bustos, del mismo género, en que se ve una mujer tejiendo (Estudio de la distinguida, 1894).

14 Las únicas mujeres en este sector eran la ya mencionada Ángela Lebrun y María Fanny Thméoy Rozée, de quien no tenemos datos.

15 La exposición fue importante en un momento en que todavía no existía un Museo de Bellas Artes. Se expusieron 28 obras de Blanes, lo que da una idea de su significación.

En comunicación con su nieta, Elena Hughes, dice tener en su casa una pintura de su abuela en la que el rostro de dos niños emerge de un entorno floral. La entrevistada comenta que, en los años en los que convivió con su abuela, esta nunca pintó ni comentó que le interesara especialmente la pintura (comunicación personal, 10 de abril, 2020). 
pone en boca de la protagonista las limitaciones de la mujer que pretendía desarrollar una actividad en forma profesional, refiriéndose justamente a la pintura:

Mientras creyeron que iba a pintar flores y otras monaditas, nadie dijo una palabra, pero cuando les manifesté la necesidad de modelos y hablé de exponer mis obras, estalló la tormenta. Mi suegro me dijo que tal cosa era ridícula e inconveniente en una señora de mi categoría [...]. (Citado en Barrán, 2015, p. 363)

El periódico católico El Amigo del Obrero siguió la exposición atentamente, siempre con palabras elogiosas. Las breves líneas que dedicó a la sección especial marcan justamente esa frontera:

[...] ha impresionado más favorablemente, ha sido el salón dedicado á las obras de las señoras Carolina Zumarán de Sienra,17 Josefina Arocena de O’Neil, Matilde Regalia de Roosen, Josefina Cibils de Miquel, María García Lagos de Hughes, Albana Illa de Secco y las señoritas María Elena Barreira, Elina García Gómez, María Crosta y María Perez y de muchas otras que lamentamos no recordar en este momento. («Un gran triunfo», 1908, p. 2)

El cronista registró algunos nombres y no pareció importarle demasiado olvidar algunos otros. Las damas de la alta sociedad eran un conjunto, parecían no ser individualidades dignas de ser recordadas siquiera por su nombre propio. La omisión dice mucho en un contexto en que el arte se valoraba especialmente como la producción del artista individual, original y capaz de realizar una obra que por su singularidad le diera brillo propio. En la conferencia que el organizador de la muestra, Raúl Montero Bustamante, brindó en el Club Católico un mes después de la inauguración, se refirió elogiosamente a los artistas nacionales expuestos y no hizo comentarios sobre la sala de las damas, y si los hizo el periodista no consideró que fuera un aporte mencionarlo («Sobre el arte», 1908).

La clase y el género condicionaban su presencia en una exposición en la que los límites entre lo público y lo privado, el amateurismo o la profesionalización de las actividades tenían escenarios bien claros. Como señala Peruchena (2010), «subyace el convencimiento de que lo que se pretendía de las mujeres educadas no apuntaba al desarrollo de una actuación pública autónoma» (p. 245). Podían estudiar pintura porque tenían disponibilidad económica y tiempo y porque era una de las actividades que les estaban habilitadas, pero siempre y cuando se mantuvieran en el estatus de aficionadas; 
no importaban los talentos. De las pintoras que participaban en la sección especial no se esperaba nada de eso; no serían pintoras profesionales, no vivirían de la pintura ni tendrían oportunidades de ser registradas como sujetos singulares. Sus obras se mantuvieron justamente en esos espacios privados, con excepción de la de Matilde Regalía de Roosen, que tuvo la singular situación de estar expuesta en la que había sido su casa.

El Museo Romántico es una de las sedes del Museo Histórico Nacional, alojado en la Casa de Montero o Casa Roosen, una de las viviendas más lujosas e importantes del Montevideo del siglo XIX. Construida en 1831 por el arquitecto José Toribio, fue residencia familiar de los Montero y sus descendientes hasta que en 1948 pasó a manos del Estado, con miras a transformarse en Museo. A fines del XIX era la vivienda de una descendiente de los Montero, Matilde Regalía, casada en 1889 con el doctor Germán Roosen (Goldaracena, 1981). La familia vivía entonces en la planta noble, y las habitaciones de la planta baja, sobre la calle 25 de Mayo, estaban alquiladas a distintos emprendimientos comerciales. Allí funcionó la primera sala de cine montevideana, el Salón Rouge. La dueña de casa, Matilde Regalía de Roosen ( ¿-1950),18 tenía, según cuenta Josefina Lerena de Blixen, uno de los salones más interesantes del Montevideo del novecientos; allí se escuchaba música, se conversaba y se reunía la intelectualidad montevideana (Lerena de Blixen, 2006, p. 82). ${ }^{19}$

$\mathrm{Al}$ año siguiente de morir la señora Matilde, sus hijos donaron al Museo Histórico una serie de piezas, entre las cuales se encontraban tres obras realizadas por la artista aficionada, así como retratos de ella, de su esposo y de sus abuelos, Antonio Montero y Matilde Raña de Montero. ${ }^{20}$ Dos de esas pinturas están en una de las salas del que fue su domicilio. Composición al óleo ${ }^{21}$ muestra, frente a un paisaje marino, a una joven que nos mira y se apoya sobre lo que podría ser el muro de un paseo costero, en el que se desparraman flores blancas. La muchacha, enteramente vestida de blanco, tiene guantes y una mantilla del mismo color. La otra pintura, Marina, ${ }^{22}$ igualmente contenida en un marco dorado, también se ubica frente a una playa sobrevolada por gaviotas; las figuras

La activa Matilde Regalía integró varias comisiones de señoras, patronatos y sociedades de beneficencia. Uno de sus proyectos más ambiciosos fue lo que habría sido el primer largometraje uruguayo de carácter histórico, que tendría a Artigas como protagonista. Juan Zorrilla de San Martín y Raúl Montero Bustamante eran parte del proyecto, y la señora Matilde, la directora (Torello, 2018).

Consultada la nieta de Matilde Regalía, la señora Matilde Hughes, destaca la importancia que la música tenía en la familia, mucho más que la pintura. La sala de música familiar tenía, además del piano, un arpa y un armonio (comunicación personal, 9 de abril, 2020).

Entre las obras donadas hay un retrato de la señora Matilde Regalía de Roosen, actualmente en la Sala de Música del Museo Romántico, obra de Daniel Hernández, y otro del señor Roosen, obra del pintor checo radicado en la Argentina Darío Rappoport. 
son una chica joven vestida de blanco que se recuesta en los hombros de una mujer un poco mayor vestida de negro. Flores y damas eran los encantadores temas en los que las señoras podían incursionar.

Dos pinturas de Lola Rhode realizadas sobre seda, Primavera ${ }^{23}$ e Invitación al vals, ${ }^{24}$ fueron donados en 1991 al MHN por su nieta, la escritora uruguaya Dora Isella Russel (Carpeta de Antecedentes MHN 3919. Libro 3. Folio 130). La donación estaba integrada por medallas de la escritora y dos muñecas. Lola Rhode presumiblemente nació en la Argentina, ya que su nieta era argentina y llegó al Uruguay con su familia en 1933, a los ocho años de edad. La seda como soporte, por su propia delicadeza y fragilidad, parece corresponderse a lo que el imaginario decimonónico entendía por lo femenino. La factura de ambas es claramente tributaria del modernismo: la sinuosidad de las líneas, las tintas casi planas, la luz diáfana. En Primavera (1917), las protagonistas son cuatro jóvenes vestidas de blanco que caminan por un sendero junto al cual se ven árboles de flores blancas; ellas conversan y ríen sin preocupaciones. La otra pintura, Invitación al vals (1915), muestra a una pareja. Una joven de vestido rosa, guantes blancos y abanico se vuelve hacia el joven que entra en la habitación descorriendo una cortina, lo que sugiere el baile que transcurre en la habitación contigua. Los muebles, el biombo, un ramo de flores que cae al suelo son notas que sugieren el ambiente elegante y mundano que la pintora trata de transmitir.

Las pocas obras de pintoras que hay en el acervo del $\mathrm{MHN}^{25}$ no llegaron porque fueran valoradas plásticamente, y es probable que la pintura de Regalía esté expuesta por haber sido el Museo Romántico su casa. Los cuadros de Regalía y de Rhode fueron donaciones de los años 1951 y 1991 respectivamente, momento en que su destino podría haber sido el Museo de Bellas Artes, hoy Museo Nacional de Artes Visuales. En cambio, los donantes entendieron, que junto a otros retratos, medallas o muñecas, podían ser testimonio de una forma de vida de los sectores altos de la sociedad uruguaya y no obras merecedoras de un museo de artes plásticas. Como señaló certeramente Nochlin (1971),

Primavera, 1917. Óleo sobre seda, $1400 \times 1050 \mathrm{~cm}$. sefa Palacios (una pintura histórica), Carmen Árraga (dos retratos), Elvira Reyes (retrato del padre) y Matilde Regalía de Roosen (dos óleos). También hay obras de artistas del siglo XX: Carmen Garayalde (una pintura histórica en coautoría con Astapenco y Polleri), Amalia Polleri (una pintura histórica en coautoría con Garayalde y Astapenco, una pintura costumbrista), Leonie Matthis (dos paisajes de la época colonial), Lola Rhode (dos obras), Renée Geille Castro (14 óleos de paisajes y pintura histórica). Datos proporcionados por la profesora Laura Irigoyen. 
[...] el arte no es una tarea autónoma y libre de un individuo superdotado, «incluido» por los artistas anteriores y, de forma más vaga y superficial, por las «fuerzas sociales». Lejos de esto, la situación global de la producción artística, tanto en lo que respecta al desarrollo del creador como en lo relativo a la naturaleza y la calidad de la propia obra de arte, se encuadra en una situación social, es un elemento clave de esta estructura social y está condicionada y determinada por instituciones sociales concretas y definibles, ya sean academias de arte, sistemas de mecenazgo o mitologías sobre el creador divino o el artista como «supermacho»o marginado social (p. 289).

El estudio de las mujeres que produjeron arte en el siglo XIX, nos exige entonces repensar las categorías en que ordenamos las artes, las fuentes a las que recurrimos, el valor que asignamos a las rupturas y los cambios en los lenguajes. El desafío más difícil es probablemente aceptar que nuestro objeto de estudio, las producciones artísticas de mujeres, existen escasamente. Es un problema nuevo para la historia del arte, que ya en los años setenta advertían las primeras investigadoras feministas. Como señala De Diego (2002): «Debían aprender a moverse dentro de una historia del arte sin objetos o con escasos objetos no solo en su pura fisicidad - pocas obras conservadas - sino hasta a través de noticias en documentos» (p. 437).

La invisibilización de la que fueron objeto las desplazó no solamente de la historiografía, sino también de los espacios de legitimación del arte, como los museos.

\section{Bibliografía}

Barrán, J. P. (2015). Historia de la sensibilidad en el Uruguay. Montevideo: Ediciones de la Banda Oriental.

Barrios Pintos, A. (2011). De tierra adentro: Escritores, músicos y artistas plásticos del interior uruguayo. Montevideo: Planeta.

Blanes, J.M. (1961). [Carta a Mauricio Blanes]. Archivo General de la Nación (Archivo Blanes en AGN, Carpeta 1855-1879, Pieza 8). Montevideo, Uruguay.

Carve, L. (12 de enero, 1915). [Carta a la Srta. Elvira Reyes]. Museo de Historia Nacional (Carpeta 502., Antecedentes). Montevideo, Uruguay.

Catálogo de la Primera Exposición de Pintores Nacionales, Club Católico, Montevideo (s/f). La Buena Prensa.

Chadwick, W. (2007). Women, art, and society. Londres: Thames \& Hudson.

Cuadro, I. (2018). Feminismos y política en el Uruguay del novecientos. Montevideo: Ediciones de la Banda Oriental. 
de Diego, E. (2002). Figuras de la diferencia. En V. Bozal (ed.), Historia de las ideas estéticas y de las teorías artísticas contemporáneas: Volumen 2. Madrid: La Balsa de la Medusa.

De Diego, E. (2009). La mujer y la pintura del siglo XIX español. Madrid: Cátedra. Estudio de la distinguida Srta. Bustos. (7 de octubre, 1894). Montevideo Cómico, 8. Ferreira, F., hijo. (20 de abril, 1854). [Artículo]. El Eco de la Juventud, 14.

Figari, P. (1965). Educación y arte. Montevideo: Ministerio Instrucción Pública. (Colección Clásicos Uruguayos, 81).

Goldaracena, R. (1981). Libro de los linajes: Tomo 3. Montevideo: Arca.

Juan de los Palotes (15 de agosto, 1908). Bohemia, 7.

Laroche, W.E. (1961). Derrotero para una historia del arte en el Uruguay: Tomo 2. Montevideo: Monteverde.

Laroche, W.E. (1975). Introducción. En Biblioteca de Poder Legislativo (comp.), Plásticos uruguayos. Montevideo: Biblioteca del Poder Legislativo.

Laroche, W.E. (18 de abril, 1958). Apuntes para la iconografía de la cruzada del 19 de abril de 1825. El Plata.

Lerena de Blixen, J. (2006). Novecientos. Montevideo: Ediciones de la Banda Oriental.

María Luisa Velazco y Josefina Cibils. (12 de mayo, 1887). La Ilustración del Plata, 1(6).

Mitchell, W.J.T. (2017). ¿Qué quieren las imágenes? Buenos Aires: Sans Soleil.

Nochlin, L. (1971). ¿Por qué no ha habido grandes mujeres artistas? Recuperado de https://www.vitoria-gasteiz.org/wb021/http/contenidosEstaticos/adjuntos/es/87/78/48778.pdf.

Nuestra galería artística. (30 de setiembre, 1894). Montevideo Cómico, 1(7), p. 51.

Parker, R. y Pollock, G. (2013). Old mistresses: Women, art and ideology. Nueva York: Taurus.

Peluffo Linari, G. (1997). Producción iconográfica y vida privada (1830-1860). En J.P. Barrán, G. Caetano, T. Porzecanski, T. (dirs.), Historia de la vida privada en el Uruguay: Entre la honra y el desorden. 1780-1870. Montevideo: Taurus.

Peluffo Linari, G. (2006). Pedro Figari: Arte e industria en el novecientos. Montevideo: Ministerio Relaciones Exteriores. (Homenaje, 6).

Peluffo Linari, G. (2015). Historia de la pintura en el Uruguay: Tomo 1. Montevideo: Ediciones de la Banda Oriental.

Peruchena, L. (2010). Buena madre, virtuosa ciudadana: Maternidad y rol político de las mujeres de las élites (Uruguay, 1875-1905). Montevideo: Rebeca Linke.

Pivel Devoto, J. (1952). A propósito de un cuadro sobre los Treinta y Tres Orientales. El Debate, 28(20).

Pollock, G. (2015). Visión y diferencia. Buenos Aires: Fiordo.

Reyes, E. (22 de enero, 1915). [Carta a Luis Carve]. Museo de Historia Nacional (Carpeta 502, Antecedentes). Montevideo, Uruguay. 
Sobre el arte nacional. (8 de agosto, 1908). El Amigo del Obrero: Órgano de los Círculos Católicos Obreros del Uruguay, p. 1.

Torello, G. (2018). La conquista del espacio: Cine silente uruguayo (1915-1932). Montevideo: Yaugurú.

Un gran triunfo artístico-nacional: La exposición del Club. (11 de julio, 1908). El Amigo del Obrero: Órgano de los Círculos Católicos Obreros del Uruguay, p. 2. 